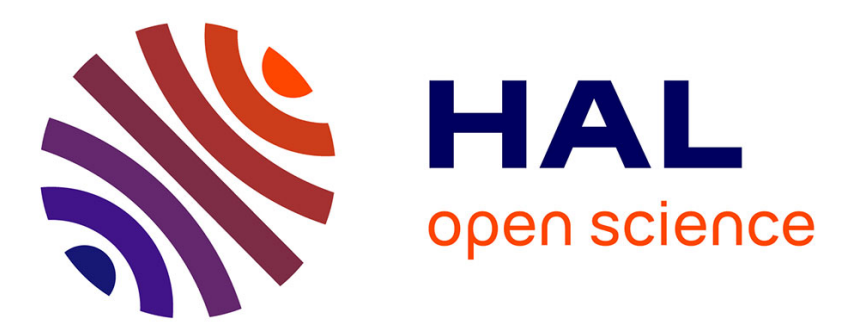

\title{
Contribution à l'étude d'une plante haploïde de pommier (Malus pumila, Mill.). Etude descriptive et comparaison avec des clones de ploïdie différente. II. - Aptitude à la reprise au greffage
}

\author{
Dominique Noiton, Claude Coquen, Yves Lespinasse
}

\section{To cite this version:}

Dominique Noiton, Claude Coquen, Yves Lespinasse. Contribution à l'étude d'une plante haploïde de pommier (Malus pumila, Mill.). Etude descriptive et comparaison avec des clones de ploïdie différente. II. - Aptitude à la reprise au greffage. Agronomie, 1986, 6 (7), pp.665-674. hal-00884923

\section{HAL Id: hal-00884923 https://hal.science/hal-00884923}

Submitted on 1 Jan 1986

HAL is a multi-disciplinary open access archive for the deposit and dissemination of scientific research documents, whether they are published or not. The documents may come from teaching and research institutions in France or abroad, or from public or private research centers.
L'archive ouverte pluridisciplinaire HAL, est destinée au dépôt et à la diffusion de documents scientifiques de niveau recherche, publiés ou non, émanant des établissements d'enseignement et de recherche français ou étrangers, des laboratoires publics ou privés. 


\title{
Contribution à l'étude d'une plante haploïde de pommier (Malus pumila, Mill.). Etude descrip- tive et comparaison avec des clones de ploïdie différente. II. - Aptitude à la reprise au greffage
}

\author{
Dominique NOITON $\left({ }^{b}\right)$, Claude COQUEN $\left({ }^{*}\right) \&$ Yves LESPINASSE \\ I.N.R.A., Station de Recherches d'Arboriculture fruitière, Beaucouzé, F 49000 Angers \\ (*) Laboratoire de Biologie végétale, U.E.R. des Sciences et Techniques, Boulevard Lavoisier, F 49045 Angers \\ Cedex
}

RÉSUMÉ

\begin{abstract}
La multiplication en serre de la plante haploïde de pommier par greffage sur des porte-greffes diploïdes issus de semis pose de nombreux problèmes. L'originalité du clone haploïde nous a conduits à comparer ses réactions au greffage avec celles de clones apparentés diploïde et tétraplö̈de.

L'étude histologique des phénomènes de cicatrisation a permis d'écarter, d'une part, la possibilité de l'existence d'une anomalie dans la structure de la tige du sujet haploïde et, d'autre part, l'hypothèse d'une incompatibilité due à la différence de niveau de ploïdie entre le porte-greffe et le greffon. Par contre, la grande inégalité entre les diamètres des deux symbiotes semble retarder les processus d'union et pourrait être à l'origine d'une mauvaise nutrition du greffon haplö̈de. Des essais comparatifs portant sur des porte-greffes conférant différentes vigueurs ont confirmé ces observations. Le porte-greffe " Malling 9 », de vigueur faible et d'un diamètre proche de celui du greffon, est désormais utilisé pour la multiplication du clone haploïde.
\end{abstract}

Mots clés additionnels : Histologie, relations porte-greffe-greffon.

Additional key words : Histology, rootstock-scion relationships.

\section{INTRODUCTION}

La $1^{\text {re }}$ partie de cette étude (LESPINASSE \& NOITON, 1986) a été consacrée à une comparaison de certains caractères de l'appareil végétatif, effectuée sur des plantes de ploïdie différente et de filiation proche.

Les difficultés rencontrées lors du greffage du pommier haploïde constituent un facteur limitant pour sa

( ${ }^{1}$ ) Adresse actuelle : Departement of Agronomy and Horticultural Science, University of Sydney, N.S.W. Australia 2006. multiplication végétative et, par conséquent, pour son étude approfondie (NOITON, 1981 ; 1982).

La multiplication du clone haploïde a été effectuée, en serre et au printemps, sur des porte-greffes "Francs " âgés d'un an, issus de semis de la variété " Golden Delicious ». Leur utilisation avait pour but de conférer aux greffons un maximum de vigueur lors de la « reprise » de la greffe. En règle générale, le diamètre des sujets est choisi identique à celui des greffons afin d'éviter un déséquilibre de croissance ; cette précaution ne peut pas être respectée pour les greffons haploïdes en raison de leur très faible diamètre. 
Des phénomènes d'incompatibilité dus soit à la différence de niveau de plö̈die, soit à un déséquilibre de vigueur entre le porte-greffe et le greffon, pourraient être à l'origine des mauvais résultats obtenus; ceci nous a conduits à entreprendre une étude comparative, essentiellement histologique, de la « reprise » au greffage de clones haploïde, diploïde et tétraploïde.

Cette étude a été complétée par une expérimentation, développée en pépinière et à l'automne, faisant appel à une gamme de porte-greffes de vigueur différente.

\section{MATÉRIEL ET MÉTHODES}

L'expérimentation conduite en pépinière est effectuée à l'aide des porte-greffes suivants :

- le «Malling 27 » $($ 13 $\times$ M9), porte-greffe très nanisant qui donne aux greffons 2 fois moins de vigueur que le « Malling 9 »,

- le « Malling 9 » (« Paradis Jaune de Metz »), peu vigoureux,

- le «Malling 26 »(M16 × M9) qui confère aux greffons une vigueur moyenne avec une forte croissance les $1^{\text {res }}$ années.

Les greffons comportent tous dans leur filiation la variété «Delicious » (LESPINASSE \& NOITON, 1986, tabl. 1). Le clone haploïde est issu du clone diploïde «Topred Delicious »; le clone tétraploïde isolé par DERMEN aux U.S.A., résulte d'un doublement chromosomique spontané.

En serre et au printemps, le type de greffe retenu est la greffe anglaise avec languette (fig. 1). Le greffon mesure $5 \mathrm{~cm}$ de long et porte 2 bourgeons ; l'extrémité basale est taillée en biseau simple puis fendue longitudinalement en son milieu sur une longueur de $5 \mathrm{~mm}$. Le porte-greffe reçoit une entaille équivalente mais sur le côté. Les 2 languettes ainsi déterminées s'encastrent l'une dans l'autte. Le point de greffe est ensuite ligaturé et mastiqué.

Selon le niveau du prélèvement de l'échantillon le long de la greffe, la disposition des 2 symbiotes corres-

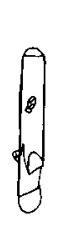

G
PG

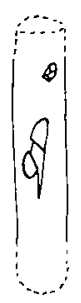

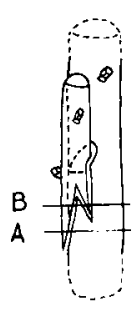

$G+P G$

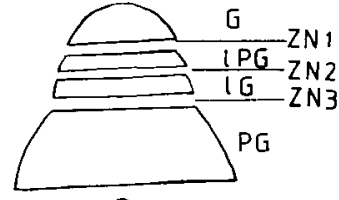

B

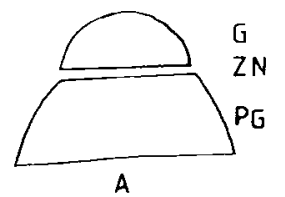

Figure 1

Greffe anglaise avec languette et disposition des 2 symbiotes.

Whip-and-tongue graft and arrangement of the 2 symbionts.

$A=$ niveau inférieur de la greffe; lower part of the graft.

$B \quad=$ niveau supérieur de la greffe; upper part of the graft.

$G \quad=$ greffon ; scion.

$P G \quad=$ porte-greffe; rootstock

$G+P G=$ union des 2 symbiotes; union of the 2 symbionts.

$l P G=$ languette du porte-greffe; tongue of the rootstock.

$l G \quad=$ languette du greffon; tongue of the scion.

$Z N=$ zone de néoformation; zone of new formation. pond soit à celle d'une fente simple (A), soit à celle d'une double fente (B) (fig. 1).

Les essais comparatifs portant sur les clones de ploïdie différente ont été réalisés au printemps et en serre. L'observation du comportement des divers greffons sur les porte-greffes «Francs » nous a conduits à entreprendre une étude histologique détaillée du point de greffe. Les échantillons, mesurant $8 \mathrm{~mm}$ de hauteur, sont sectionnés dans le sens longitudinal de façon à ne conserver que la partie intéressant la zone de jonction des 2 symbiotes. Nous avons effectué 3 séries de prélèvements, sur des greffes âgées de 1 mois à 1 an et demi, correspondant à différentes étapes du développement du greffon : œil dormant, bourgeon au stade " rosette " (couronne de 3 ou 4 feuilles) et " pousse allongée $\gg$ (rameau feuillé de 10 à $17 \mathrm{~cm}$ ). Les dates de greffage, identiques pour les clones diploïde et tétraploïde, varient pour le clone haploïde (tabl. 1).

TABLEAU 1

Age de la greffe lors des 3 prélèvements.

Scion age for each of the 3 samplings.

\begin{tabular}{lcc} 
Nature du clone $\quad$ Dates du greffage & $\begin{array}{c}\text { Age de la greffe } \\
\text { (en jours) }\end{array}$ \\
\hline
\end{tabular}

$1^{\text {er }}$ prélèvement : 29 avril 1981 - stade œil dormant

$\begin{array}{lrr}\text { diploïde } & 2 \text { avril } 1981 & 27 \mathbf{j} \\ \text { haploïde } & 2 \text { avril } 1981 & 27 \mathrm{j} \\ & 25 \text { février } 1981 & 63 \mathrm{j} \\ \text { tétraplö̈de } & 2 \text { avril } 1981 & 27 \mathrm{j}\end{array}$

$2^{\text {e }}$ prélèvement : 26 mai 1981 - stade « rosette »

$\begin{array}{lrr}\text { diploïde } & 2 \text { avril } 1981 & 55 \mathrm{j} \\ \text { haploïde } & 6 \text { février } 1981 & 109 \mathrm{j} \\ \text { tétraplö̈de } & 2 \text { avril } 1981 & 55 \mathrm{j}\end{array}$

$3^{\mathrm{e}}$ prélèvement : 29 juillet 1981 - stade «pousse longue »

$\begin{array}{lrr}\text { diploïde } & 2 \text { avril } 1981 & 117 \mathrm{j} \\ \text { haploïde } & 11 \text { mars } 1980 & 496 \mathrm{j} \\ \text { tétraploïde } & 2 \text { avril } 1981 & 117 \mathrm{j}\end{array}$

L'étude histologique a été réalisée à partir de coupes en série, colorées au bleu de méthylène-rouge de ruthénium (LOCQUIN \& LANGERON, 1978).

Les essais relatifs à l'effet de la différence de vigueur des porte-greffes ont eu lieu à l'automne (octobre 1981), en pépinière, sur des lots de 5 plantes. Des observations morphologiques (taux de reprise, vigueur des pousses, équilibre entre les 2 symbiotes) réalisées 8 mois plus tard ont permis de comparer les résultats.

\section{RÉSULTATS}

\section{A. Etude comparative de la structure histologique du point de greffe}

L'année même du greffage, la « reprise » des greffons diploïdes se manifeste normalement par le développement du bourgeon supérieur en rameau feuillé ; dans le cas, rare, où le $2^{\mathrm{e}}$ bourgeon « débourre », il est rapidement inhibé. Le taux de « reprise » s'élève à 100 p. 100.

Pendant la même période, chez le clone haplö̈de, les réactions des bourgeons varient selon le niveau de pré- 
lèvement des greffons sur le rameau-mère : le bourgeon apical amorce un début de développement qui se limite à la formation d'une couronne de 3 ou 4 feuilles ou « rosette », tandis que les bourgeons axillaires restent à l'état latent. La $2^{e}$ année, le taux de reprise des greffes ne s'élève qu'à 20 p. 100 ; dans ce cas, les 2 bourgeons débourrent et se transforment en rameaux feuillés.

Enfin, chez le clone tétraploüde, la « reprise »des greffons a lieu dès la $1^{\text {re }}$ année, comme chez le clone diploïde, mais la croissance des rameaux feuillés est irrégulière et le taux de réussite n'atteint que 50 p. 100 .

Avant d'examiner la structure histologique des différentes zones de jonction, il est indispensable de décrire celle d'une tige de pommier diploïde (fig. 2). De la périphérie vers le centre, nous observons successivement : un épiderme mince, un collenchyme tangentiel continu, un parenchyme cortical fondamental peu épais, des îlots de fibres péricycliques, un anneau continu de formations secondaires libéro-ligneuses, de nombreux pôles de bois primaire et une moelle cellulosique réduite.

Chez le clone haploïde, le cortex est sinueux et plus épais, les cellules du liber et du bois secondaires sont nettement plus petites et les pôles de bois primaire irréguliers. La structure histologique de la tige du clone tétraploïde est sensiblement identique à celle du clone témoin diploïde.

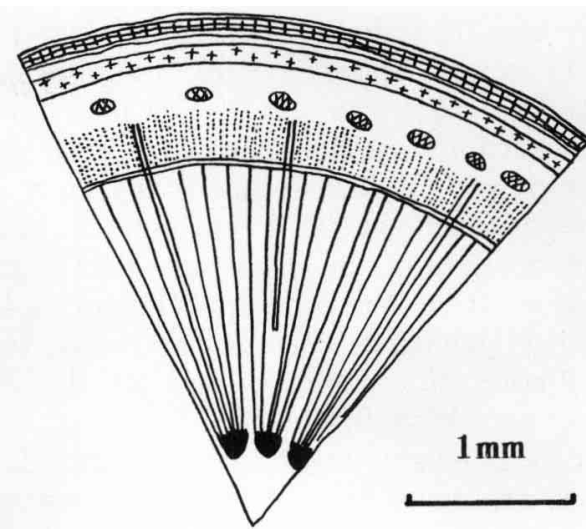

Figure 2

Structure histologique d'une tige de pommier diploide âgé d'I an. Histology of a 1-year old diploid apple stem.

\section{Greffon témoin diploïde}

Au stade « ail dormant » (1 mois après la greffe), la blessure est refermée, le périderme est continu. Les parenchymes corticaux, également en continuité, prolifèrent et sont à l'origine du cal de cicatrisation qui obture partiellement la brèche ; une lacune centrale est
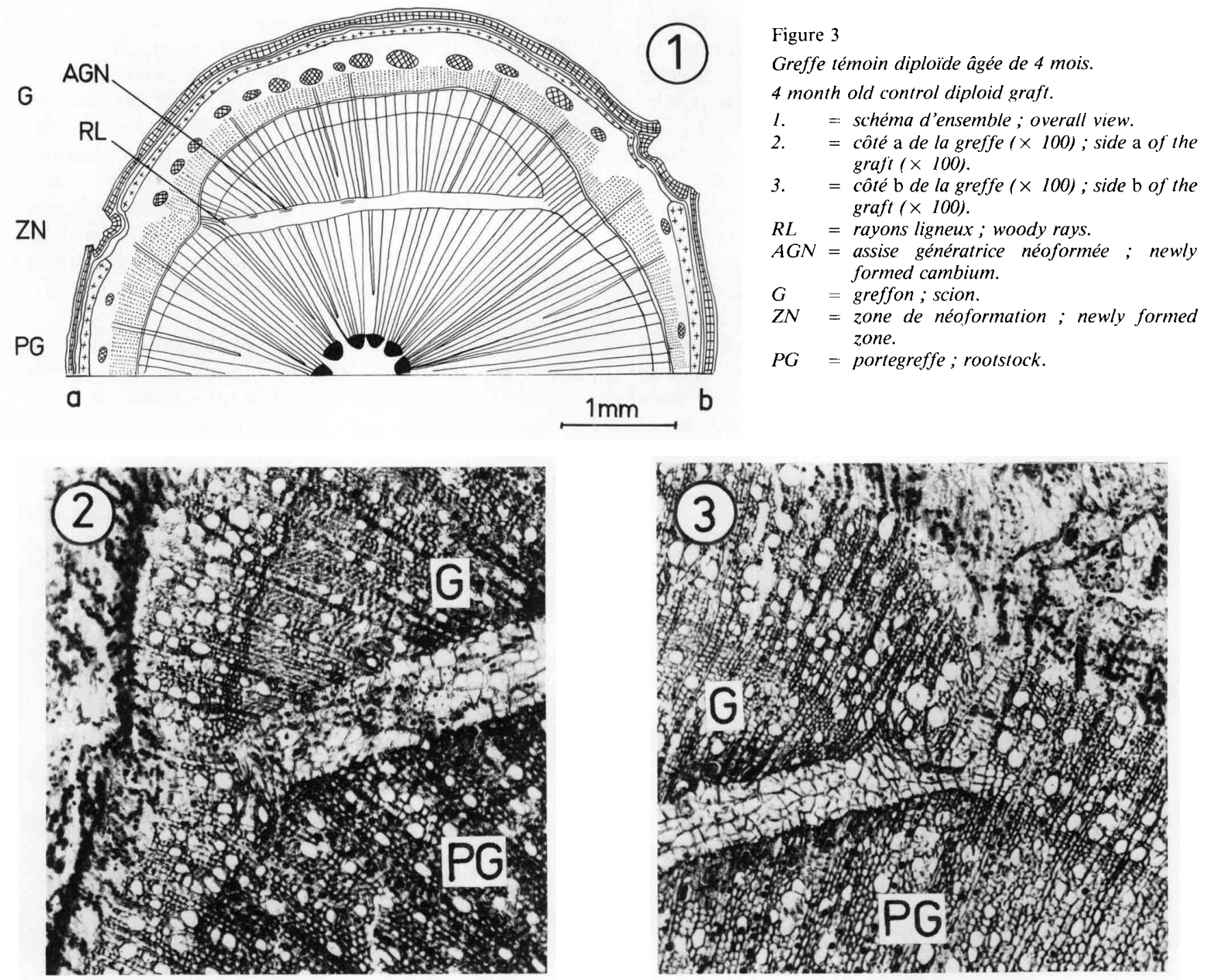
encore présente. Les cambiums libéro-ligneux du portegreffe et du greffon tendent à se joindre ; à ce stade, du bois secondaire néoformé est déjà visible. La reprise d'activité des cambiums libéro-ligneux qui se manifeste au printemps par un accroissement annulaire du bois secondaire, est régulière chez le porte-greffe, très faible et localisée à proximité de la blessure chez le greffon.

Au stade « rosette » ( 2 mois après la greffe), les cambiums libéro-ligneux, en parfaite continuité, fonctionnent des 2 côtés de la zone de jonction; bois et liber secondaires sont bien différenciés.

Au stade «pousse allongée » (4 mois après la greffe) (fig. 3), les processus de cicatrisation se poursuivent ; la symbiose est parfaite. Du collenchyme commence à se différencier sous le phelloderme néoformé ; l'anneau d'accroissement du bois secondaire de printemps est continu et régulier. A la périphérie du cal, du côté $a$ de la greffe, quelques files de cellules ligneuses $(R L)$ issues $\mathrm{du}$ bois secondaires du porte-greffe prolifèrent et entrent en contact avec le bois secondaire néoformé. Si la plus grande partie du cal est encore de nature cellulosique, on y observe cependant un début de sclérification centripète; de plus, quelques cellules du parenchyme cicatriciel se cloisonnent parallèlement à la blessure, constituant ainsi l'ébauche d'une zone cambiale néoformée (AGN).

\section{Greffon haploïde}

Au stade « oil dormant » (1 mois après la greffe), les tissus corticaux néoformés sont organisés comme chez le clone témoin (fig. 4) ; cependant, des traces de cellules mortes (CM) sont visibles au contact des parenchymes [ligne de démarcation de THIEL (1954), décrite également par MOSS (1962)]. Les assises génératrices libéro-ligneuses sont en continuité des 2 côtés mais n'ont pas encore fonctionné. Les tissus de cicatrisation, d'origine corticale, n'obturent pas complètement la brèche, une lacune centrale (LC) restant visible. A proximité des assises cambiales néoformées, quelques rayons ligneux cellulosiques ( $R L$ ) issus du bois secondaire du porte-greffe prolifèrent jusqu'au bois secondaire du greffon, formant à son contact une ligne de cellules écrasées. Aucune reprise d'activité de l'assise génératrice libéro-ligneuse n'est visible au niveau du greffon tandis que le bois secondaire du porte-greffe présente un accroissement normal.

Deux mois après la greffe, le greffon haploïde est toujours au stade « oeil dormant »; l'échantillon prélevé étant très petit, nous avons observé le point de greffe à 2 niveaux.

Dans la partie inférieure (fig. 5), l'organisation des tissus néoformés est plus complexe que précédemment et la brèche est entièrement comblée. Du côté $a$ (fig. $5_{1}$ et $5_{2}$ ), les cambiums libéro-ligneux prolifèrent mais la persistance de la ligne de démarcation (CM) perturbe leur jonction. Le cambium issu du porte-greffe s'interrompt brutalement et fonctionne en donnant du liber et $\mathrm{du}$ bois secondaire du porte-greffe prolifèrent et cellules cambiales. Du côté $b$ (fig. $5_{1}$ et $5_{3}$ ), il n'y a plus de cellules mortes ; les cambiums libéro-ligneux sont en continuité et s'invaginent profondément vers le centre du cal. Les cellules libériennes néoformées sont dans le prolongement du liber secondaire du porte-greffe ; le bois secondaire, très réduit, est encore indifférencié. Au centre de la zone de jonction et à proximité des zones cambiales néoformées, le cal est envahi par la prolifération du bois secondaire du porte-greffe (RL) ; on note encore la présence de cellules écrasées (CE).

Dans la partie supérieure (fig. 6), au niveau de la double fente, on observe 2 languettes : l'une, IPG diploïde (porte-greffe), l'autre IG haploïde (greffon) ; 3 cals de cicatrisation, correspondant aux zones ZN1, $\mathrm{ZN} 2$ et $\mathrm{ZN} 3$, obturent entièrement les brèches centrales. Le bois secondaire du porte-greffe ne prolifère que dans la zone de néoformation $\mathrm{ZN} 1$; dans le cal ZN3, quelques cellules du parenchyme cicatriciel présentent un début de cloisonnement parallèle à la blessure. Les cambiums libéro-ligneux sont en continuité mais leur fonctionnement est irrégulier. La reprise d'activité, à peu près nulle dans le greffon, est importante dans la languette IG ; la faible dimension des éléments ligneux nouvellement différenciés prouve leur origine haploïde.

Au stade "rosette" (4 mois après la greffe), on n'observe aucune modification importante dans l'organisation des tissus.

Il faut attendre 1 an et demi avant d'obtenir le stade «pousse allongée » (fig. 7). L'accroissement du bois secondaire est régulier et continu. Le cambium libéroligneux de la languette IG participe à la jonction des

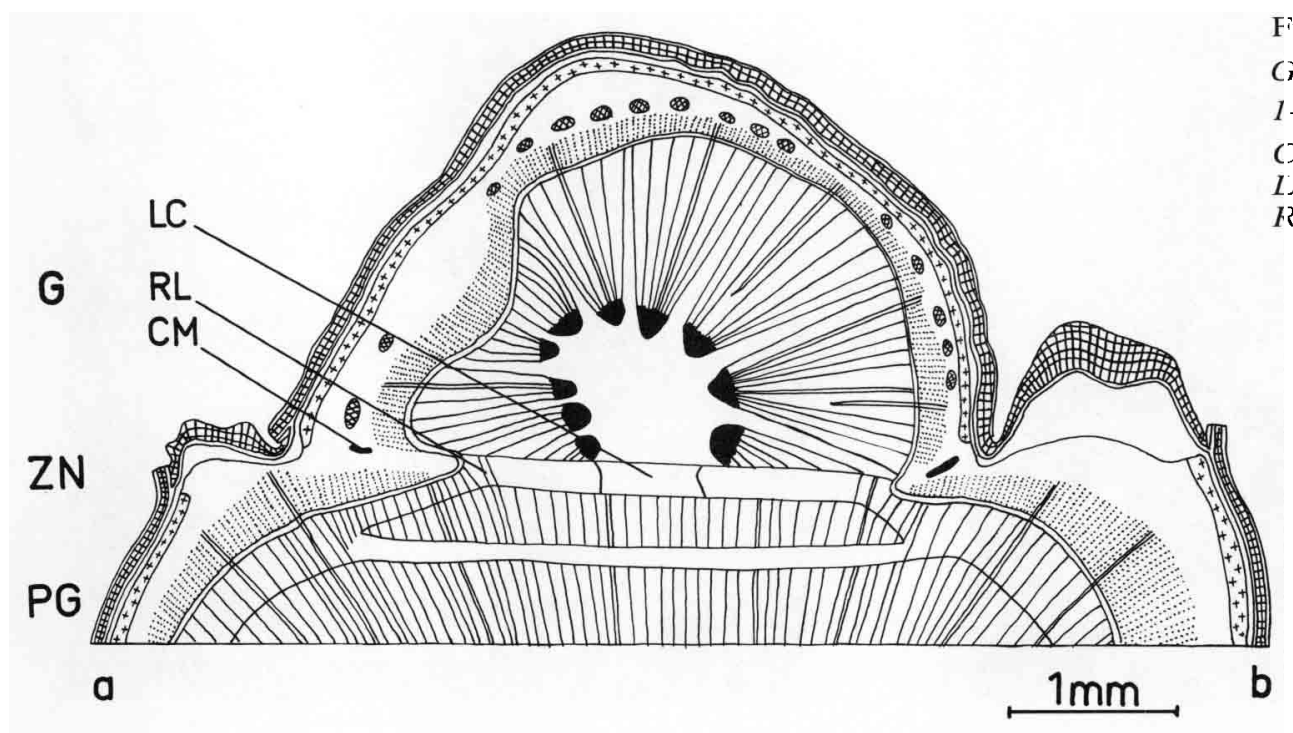

Figure 4

Greffe haploïde âgée d'l mois. 1-month old haploid graft.

$C M=$ cellules mortes; dead cells. $I . C=$ lacune centrale; central lacuna. $R L=$ rayons ligneux; woody rays. 

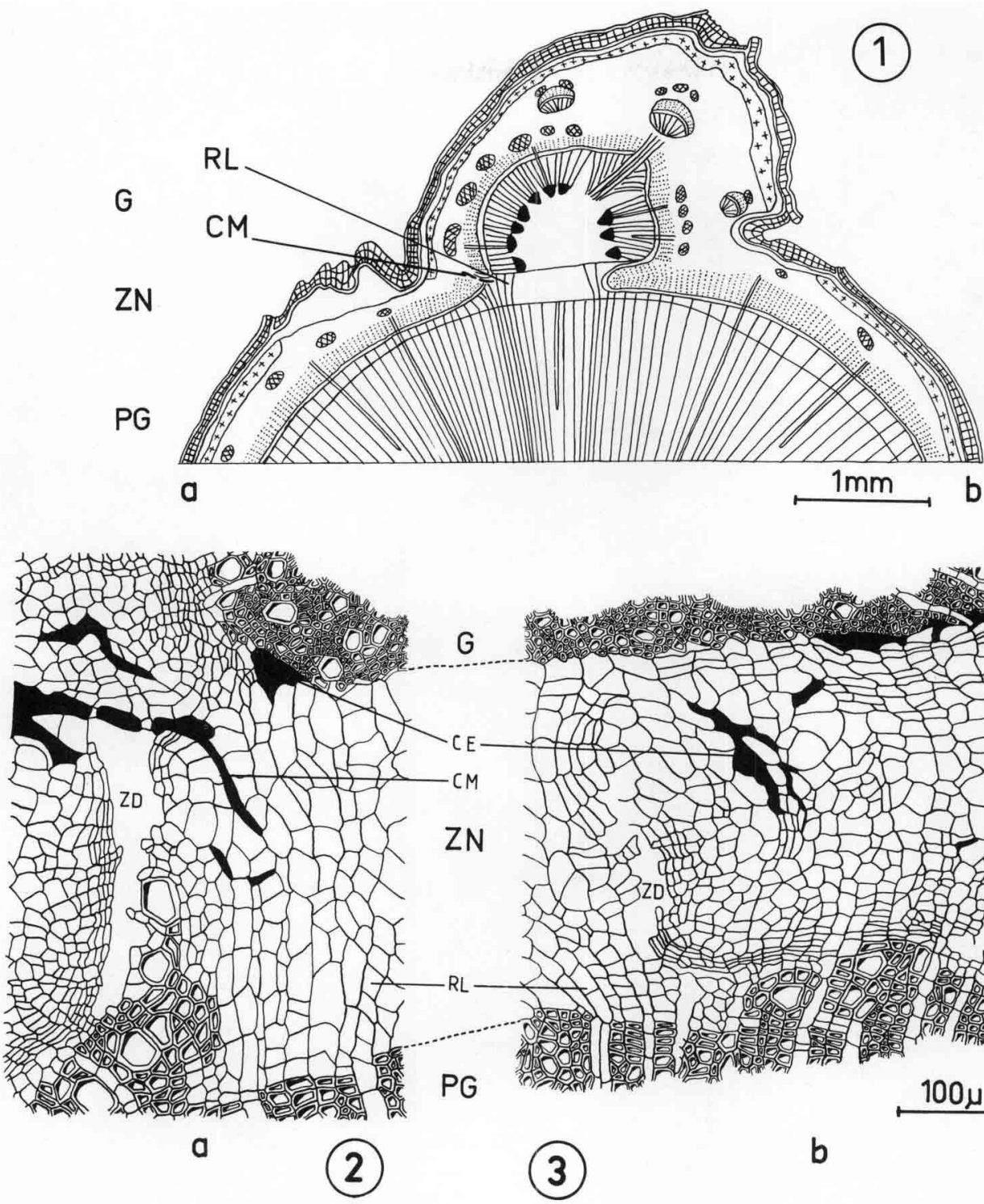

Figure 5

Greffe haploìde âgée de 2 mois, niveau inférieur de la greffe.

2-month old haploid graft, lower part of the graft.

1. = schéma d'ensemble; overall view.

2. = côté a de la greffe, détail de la zone néoformée; side a of the graft, detail of the newly formed zone.

$3 .=$ côté $\mathrm{b}$ de la greffe, détail de la zone néoformée; side $\mathrm{b}$ of the graft, detail of the newly formed zone.

$R L=$ rayons ligneux; woody rays.

$C M=$ cellules mortes; dead cells.

$C E=$ cellules écrasées; squashed cells.

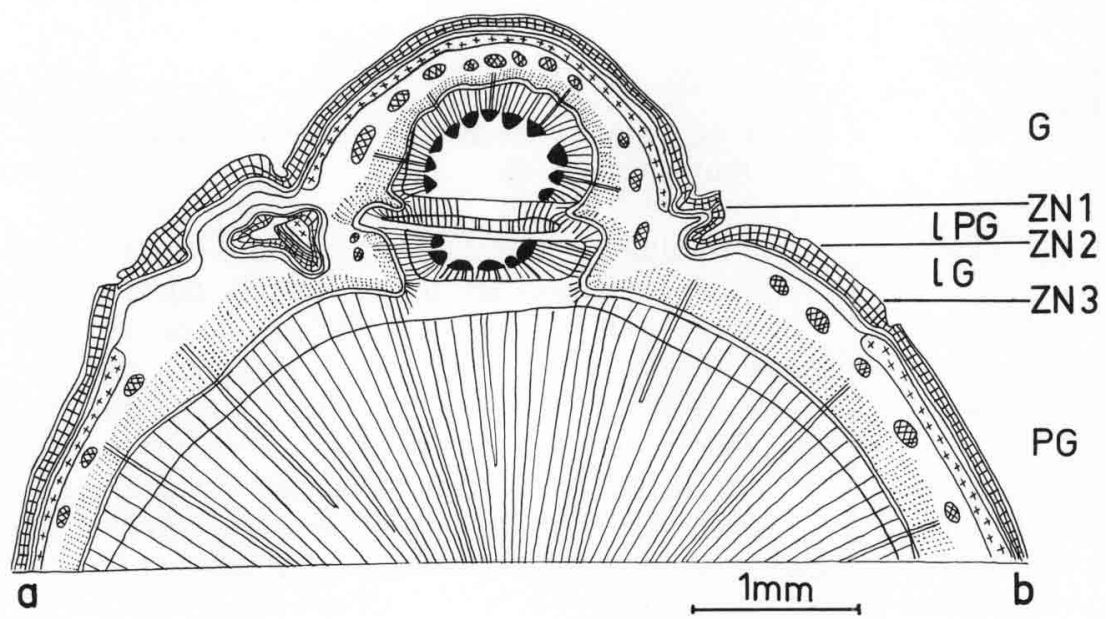

Figure 6

Greffe haploïde âgée de 2 mois, niveau supérieur de la greffe.

2-month old haploid graft, upper part of the graft. 

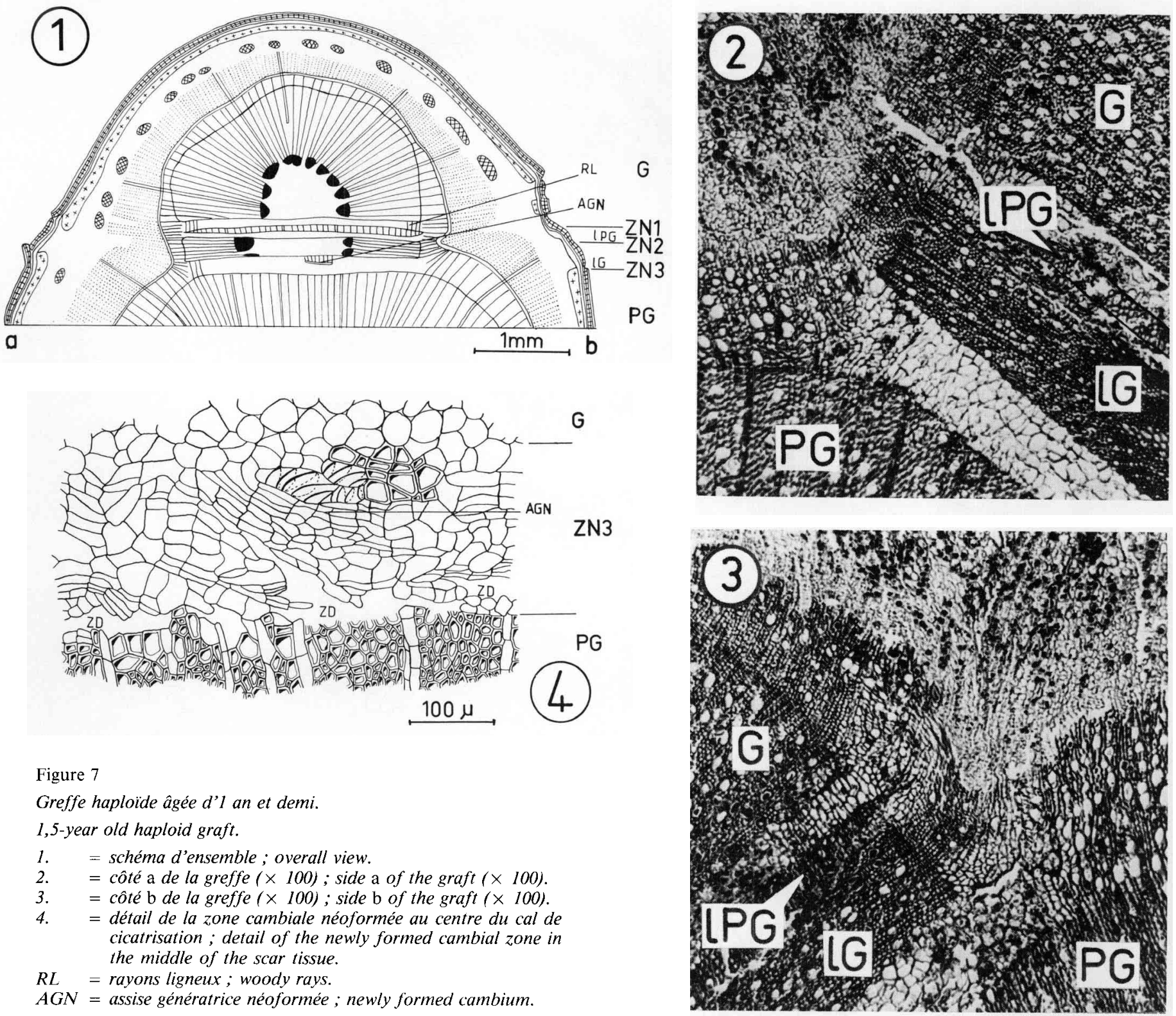

Figure 7

Greffe haploìde âgée d'l an et demi.

1,5-year old haploid graft.

1. $\quad$ = schéma d'ensemble; overall view.

2. $=$ côté a de la greffe $(\times 100) ;$ side a of the graft $(\times 100)$.

3. $=$ côté $\mathrm{b}$ de la greffe $(\times 100) ;$ side $\mathrm{b}$ of the graft $(\times 100)$.

4. = détail de la zone cambiale néoformée au centre du cal de cicatrisation; detail of the newly formed cambial zone in the middle of the scar tissue.

$R L \quad=$ rayons ligneux; woody rays.

$A G N=$ assise génératrice néoformée; newly formed cambium.

assises et le bois secondaire néoformé semble bien avoir une origine haploïde (cellules de taille réduite). Les cals sont en voie de sclérification centripète et des trachéides courtes s'y différencient par endroits. De chaque côté de la zone de néoformation, des rayons ligneux (RL) issus du bois secondaire du porte-greffe sont visibles. Au centre du cal ZN3 (fig. 7 et $7_{4}$ ), le cloisonnement parallèle à la blessure s'est poursuivi, conduisant à l'édification d'une zone cambiale fonctionnelle (AGN) ; du bois secondaire est déjà différencié.

\section{Greffon tétraploide}

Au stade « ceil dormant » (1 mois après la greffe), les tissus sont organisés comme dans la greffe témoin et des traces de la ligne de démarcation sont visibles. La lacune centrale est encore présente. La reprise d'activité des cambiums libéro-ligneux est identique à celle du témoin.

Au stade « rosette » ( 2 mois après la greffe), les tissus corticaux sont en continuité bien qu'il subsiste quelques cellules mortes; du colfenchyme se différencie sous le phelloderme néoformé. Les formations secon- daires libéro-ligneuses sont ininterrompues. Le cal cicatriciel n'obture pas complètement la brèche et une lacune centrale est encore visible.

Au stade " pousse allongée » (4 mois après la greffe), l'accroissement du bois secondaire est régulier (fig. 8) et plus important qu'au niveau de la greffe témoin diploïde ; l'anneau est parfaitement continu et le cal commence à se sclérifier.

\section{B. Etude comparative de la vigueur conférée par dif- férents porte-greffes}

Les résultats concernant le taux de « reprise » des greffons haploïde et tétraploïde sur les porte-greffes «Francs» sont meilleurs lorsque le greffage est effectué en automne, en pépinière. L'homogénéité du comportement des greffes dans un même lot nous a permis de comparer le taux de reprise (tabl. 2) et la croissance des greffons sur les différents porte-greffes étudiés.

La « reprise » du clone témoin diploïde est constante quel que soit le porte-greffe ; par contre, le taux de reprise des clones haploïde et tétraploïde, très faible sur 


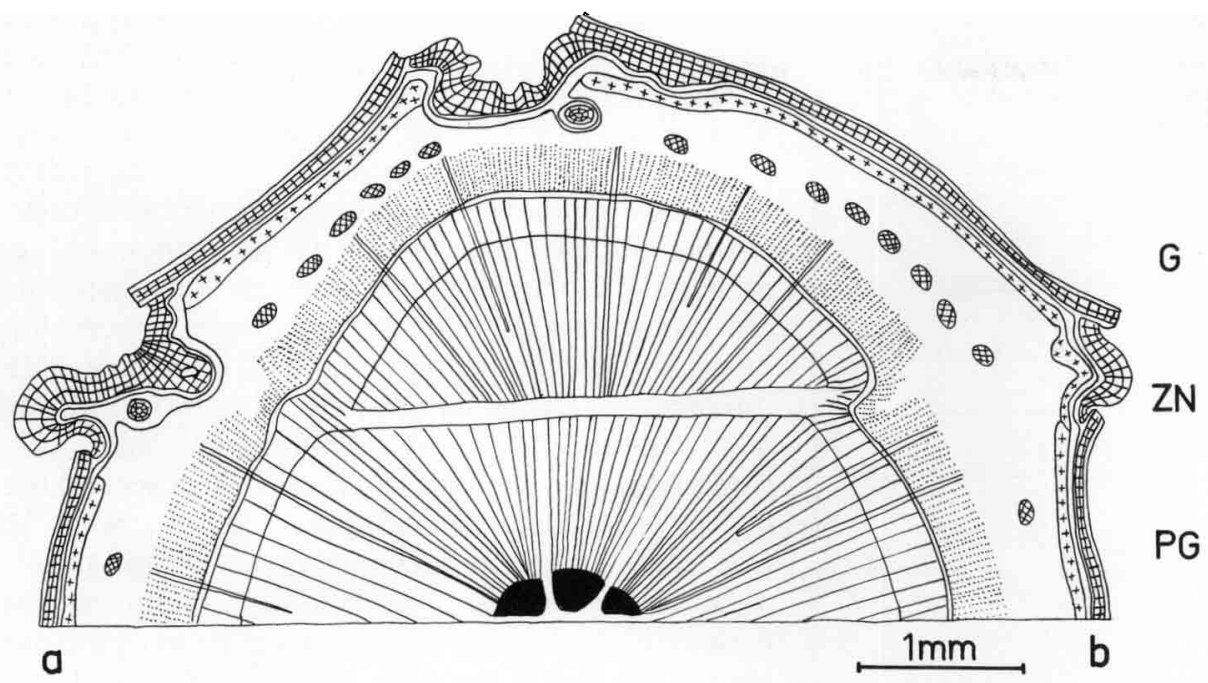

Figure 8

Greffe tétraploïde âgée de 4 mois. 4-month old tetraploid graft.

TABLEAU 2

Comparaison du taux de reprise des clones diploide, haploïde et tétraploide en fonction des porte-greffes (5 greffes par combinaison).

Bud-take comparison with diploid, haploid, tetraploid scions according to rootstock (5 grafts per combination).

\begin{tabular}{|c|c|c|c|c|}
\hline greffon & M 27 & M 9 & M 26 & «francs $»$ \\
\hline diploïde & 5 & 5 & 5 & 5 \\
\hline haploïde & 3 & 4 & 0 & 5 \\
\hline tétraploïde & 2 & 5 & 1 & 5 \\
\hline
\end{tabular}

« Malling $26 »$, moyen sur « Malling $27 »$, est beaucoup plus élevé sur « Malling 9 » et sur porte-greffe «Franc».

L'allongement des greffons est proportionnel à la vigueur conférée par les porte-greffes mais, dans le cas du clone haploïde, les réponses sont plus accentuées : les pousses, chétives sur « Malling 27 », normales sur « Malling 9 », s'allongent considérablement et restent herbacées sur les porte-greffes " Francs »; dans ce der- nier cas, les bourgeons axillaires débourrent d'une façon anarchique conduisant à un port touffu.

$\mathrm{Au}$ niveau du point de greffe, l'équilibre entre les 2 symbiotes s'établit dans le cas du « Malling 27 »et du « Malling 9 » mais la transition harmonieuse entre leur diamètre ne s'observe que sur le " Malling 9 ", tandis qu'une grande disproportion persiste entre le portegreffe « Franc » et le greffon haploïde (fig. $9_{1}, 9_{2}$ et $9_{3}$ ).

\section{DISCUSSION ET CONCLUSION}

Les résultats obtenus (tabl. 3) nous permettent d'établir une chronologie des différents processus histologiques impliqués dans le greffage des clones étudiés sur porte-greffes « Francs », en serre et au printemps.

Dans un $1^{\text {er }}$ temps, l'écorce joue un rôle essentiel dans la cicatrisation des brèches qui sont obturées progressivement par les parenchymes corticaux. Les résidus de cellules mortes localisés au contact des parenchymes néoformés - ligne de démarcation de THIEL (1954) - disparaissent rapidement chez les clones diploïde et tétraploïde. Par contre, ils subsistent beaucoup plus longtemps chez le clone haplö̈de, entraî-
Figure 9

Greffon haploide âgé d'l an.

I-year old haploid scion.

1. = sur un porte-greffe Malling 27 ; on Malling 27 rootstock.

2. = sur un porte-greffe Malling 9 ; on $\mathrm{Mal}$ ling 9 rootstock.

3. = sur un porte-greffe " franc"; on seedling rootstock.
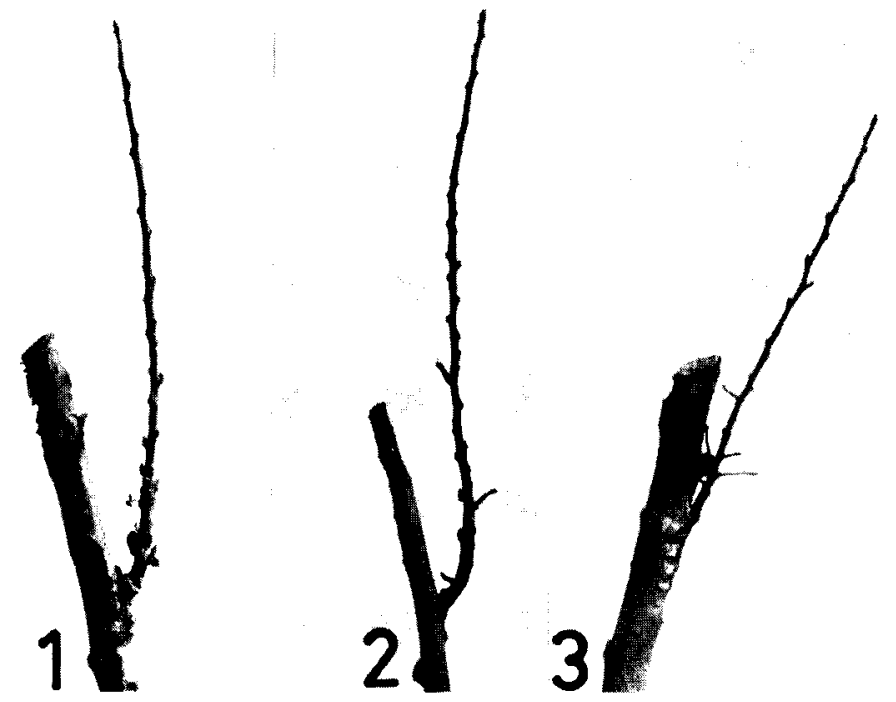


\section{TABLEAU 3}

Récapitulatif des délais nécessaires (en mois) à la mise en place des différents processus histologiques sur porte-greffes "francs " après greffage en serre et au printemps.

Summary of the waiting periods (in months) for the various histological processes on seedling rootstocks after grafting in glasshouse in spring.

\begin{tabular}{|c|c|c|c|c|}
\hline \multicolumn{2}{|c|}{$\begin{array}{l}\text { Différents } \\
\text { processus histologiques }\end{array}$} & diploïde & haploïde & tétraploïde \\
\hline \multirow{3}{*}{$\begin{array}{l}\text { continuité } \\
\text { entre les } \\
2 \text { symbiotes }\end{array}$} & \multirow{2}{*}{$\begin{array}{l}\text { - du périderme } \\
\text { - du parenchyme } \\
\text { cortical }\end{array}$} & 1 & 1 & 1 \\
\hline & & 1 & 4 & 4 \\
\hline & $\begin{array}{l}\text { - des cambiums } \\
\text { libéro-ligneux }\end{array}$ & 2 & 1 & 1 \\
\hline \multicolumn{2}{|c|}{$\begin{array}{l}\text { accroissement continu } \\
\text { du bois secondaire du greffon }\end{array}$} & 4 & 18 & 2 \\
\hline \multirow{2}{*}{$\begin{array}{l}\text { lignification du } \\
\text { bois secondaire } \\
\text { néoformé }\end{array}$} & - d'un côté & 1 & 2 & 1 \\
\hline & - des 2 côtés & 2 & 4 & 2 \\
\hline \multicolumn{2}{|c|}{$\begin{array}{l}\text { résorption totale } \\
\text { de la brèche centrale }\end{array}$} & 4 & 2 & 4 \\
\hline \multicolumn{2}{|c|}{ lignification du cal } & - & 18 & - \\
\hline \multicolumn{2}{|c|}{$\begin{array}{l}\text { formation d'un parenchyme } \\
\text { secondaire }\end{array}$} & 4 & 2 & - \\
\hline
\end{tabular}

nant des perturbations lors de l'union des assises génératrices libéro-ligneuses.

Dans un $2^{\mathrm{e}}$ temps, les cambiums libéro-ligneux des 2 symbiotes prolifèrent l'un vers l'autre par divisions radiales; des divisions tangentielles sont à l'origine du bois et du liber secondaires qui assurent ainsi la continuité des tissus conducteurs.

Dans un $3^{\mathrm{e}}$ temps, le bois secondaire du porte-greffe, récemment différencié et mis à nu lors de la greffe, prolifère en refoulant le parenchyme cicatriciel jusqu'au greffon. Ce phénomène, déjà signalé dans des greffes poirier-cognassier (THIEL, 1954) et abricotier-prunier (DELOIRE, 1982), pourrait être considéré comme une réaction de cicatrisation des éléments récents du bois.

Enfin, après la résorption totale de la brèche, le tissu cicatriciel central subit quelques modifications: le parenchyme cellulosique se sclérifie progressivement de façon centripète et des trachéides se différencient ; une assise génératrice néoformée s'organise donnant, perpendiculairement à la section, des files de cellules d'abord cellulosiques puis lignifiées. Ce dernier phénomène est à rapprocher des observations de LAUNAY (1964) dans le cas de greffes de Pinus pinaster; cet auteur avait mis en évidence, dans le tissu cicatriciel de la brèche, "l'édification spontanée d'un méristème présentant tous les caractères d'un cambium et produisant, de part et d'autre, des formations alignées mais peu différenciées en bois et liber $»$.

L'ensemble de ces phénomènes se déroule l'année même du greffage chez les clones diploïde et tétraploïde ; dès le mois de mai, le bourgeon du greffon a déjà débourré et les zones cambiales libéro-ligneuses sont fonctionnelles. Chez le clone haploüde, les modifications histologiques sont identiques mais les processus sont plus lents. A la fin du mois de mai, un début de fonctionnement des cambiums libéro-ligneux s'observe au niveau de la languette du greffon; cependant, dans le greffon lui-même, la reprise d'activité du cambium n'aura lieu qu' 1 an plus tard. N'y aurait-il pas là un phénomène de nature hormonale ? Selon ESAU (1965), l'activité cambiale de nombreuses dicotylédones ne reprend qu'après l'apparition des jeunes pousses, ce qui pourrait s'expliquer par la synthèse de substances de croissance dans le bourgeon au cours de son développement. Or, le débourrement des bourgeons des greffons diploïdes et tétraploïdes précède d'un mois l'accroissement continu du bois secondaire. Par contre, chez le clone haploïde, la néoformation de bois secondaire ne s'observe qu'l an et demi après la greffe, ce qui coïncide avec l'époque du débourrement du bourgeon.

Le fonctionnement précoce des cambiums libéroligneux de la languette du greffon est un phénomène général comme le signalent BROWN (1937) et LAUNAY (1964). Il serait dû à un hyperfonctionnement de l'assise génératrice résultant d'un "appel de sève » dans les régions blessées sous l'effet « d'hormones de blessure " sécrétées au niveau des plaies ; le phénomène serait ici exacerbé par la double fente de la greffe anglaise.

A la suite de ces observations, il convient de souligner 2 faits : d'une part, l'union des cambiums libéroligneux est toujours réalisée et, d'autre part, aucune amorce de nécrose ne se manifeste entre les 2 partenaires comme l'ont observée BRIAN \& DURON (1971) pour des greffes incompatibles de poirier-cognassier.

En conséquence, le faible taux de reprise au greffage du clone haploïde ne s'explique pas par un phénomène d'incompatibilité à l'union dû à la différence de niveau de plö̈die mais vraisemblablement par un retard considérable dans la reprise de croissance du greffon. Or, dans toutes les greffes du clone haplö̈de, nous avons constaté la prolifération abondante du bois secondaire du porte-greffe dans une grande partie du cal (près de la moitié); des cellules parenchymateuses sont alors refoulées et écrasées contre le bois secondaire du greffon, empêchant à leur niveau les échanges d'eau, d'éléments minéraux et de métabolites entre les 2 symbiotes. Cette perturbation de la nutrition du greffon a été également signalée par DELOIRE (1982) chez des greffes abricotier-prunier. La nutrition du greffon haplö̈de est mal assurée puisque les échanges se limitent aux parenchymes corticaux et aux zones cambiales ; il faudra attendre que les tissus conducteurs néoformés deviennent fonctionnels pour que les flux nutritifs s'accroissent.

Dans le cas des clones diploïde et tétraploïde, les proliférations, très réduites, n'atteignent pas le bois secondaire du greffon et les échanges ne sont pas perturbés.

L'importance de ces proliférations ligneuses peut être attribuée à la différence de diamètre des 2 partenaires. En effet, dans le cas du clone haploïde, l'inégalité des diamètres conduit le greffeur à effectuer une coupe tangentielle très superficielle dans le porte-greffe afin de faire coïncider les cambiums libéro-ligneux; une grande partie du bois secondaire récent est mise à nu et peut proliférer. Par contre, chez les clones diploïde et tétraploïde, les diamètres étant voisins, le porte-greffe est sectionné plus profondément et le bois secondaire récent mis à nu, plus réduit ; dans ce cas, la prolifération éventuelle de ce dernier sera peu importante. 
Le choix d'un porte-greffe vigoureux comme le porte-greffe «Franc» n'est donc pas nécessairement profitable à la croissance du greffon haploïde, ce que confirment nos essais sur des porte-greffes de vigueur différente. En effet, le porte-greffe « Malling 9 », de vigueur faible et d'un diamètre proche de celui du greffon haploïde s'est révélé le meilleur, suivi du «Malling 27 ». Le «Malling 26 », bien que de vigueur moyenne, ne fournit pas de bons résultats; l'aptitude assez médiocre de ce porte-greffe à la reprise au greffage est assez générale.

Ces essais réalisés en pépinière et à l'automne mettent aussi en relief l'importance de l'époque du greffage pour le clone haploïde. Comparée à la greffe de printemps, la reprise au greffage est bien meilleure lorsque la greffe est effectuée l'année précédente, fin septembre - début octobre. Avant le repos végétatif, l'automne est une période propice à l'union des 2 symbiotes (SKENE et al., 1983). Ainsi, le déroulement des proces- sus d'union plus lents chez le clone haploïde, phénomène bien mis en évidence au cours de cette étude, doit pouvoir se réaliser au cours de l'automne et vraisemblablement s'achever au printemps ; ceci reste bien sûr une hypothèse à vérifier au cours d'une étude ultérieure.

En pratique, il découle de ces résultats que le greffage du clone haplö̈de devra être réalisé en automne, sur le porte-greffe « Malling 9 ».

Reçu le 25 mars 1985. Accepté le 4 avril 1986.

\section{REMERCIEMENTS}

Nous tenons à remercier vivement Madame D. LEGER, technicienne au laboratoire de Biologie végétale de l'Université d'Angers pour son aide dans la mise au point des techniques histologiques ainsi que Monsieur POTARD, technicien à la Station d'Arboriculture fruitière pour la réalisation des greffes.

\section{RÉFÉRENCES BIBLIOGRAPHIQUES}

Brian C., Duron M., 1971. Contribution à l'étude de l'incompatibilité au greffage des combinaisons poirier-cognassier. I - Etude du processus d'union sur du matériel herbacé. Ann. Amél. Plantes, 21 (4), 445-463.

Brown A. B., 1937. Activity of the vascular cambium in relation to wounding in Balsam poplar (Populus balsamifera). Can. J. Res., Sect. C : Bot. Sci., 15, 7-31.

Deloire A., 1982. Contribution à l'étude de la greffe végétale. Histophysiologie des greffes compatibles et incompatibles de plantes cultivées dans la région méditerranéenne (arbres fruitiers, vigne...). Thèse de Doct. d'Univ. ès Sci. Nat. Univ. Sci. Tech. du Languedoc, Montpellier, $37 \mathrm{p}$.

Esau K., 1965. Plant anatomy. Ed. Wiley, London ( $2^{\mathrm{e}}$ éd.), 767 p.

Launay J., 1964. Etude physiologique et histologique du greffage chez Pinus pinaster Soland. Mém. Soc. Sci. Phys. Nat. Bordeaux, $8^{e}$ série (4), 145-252.

Lespinasse Y., Noiton D., 1986. Contribution à l'étude d'une plante haploïde de pommier (Malus pumila Mill.). Etude descriptive et comparaison avec des clones de ploïdie différente. I - Caractères végétatifs : entrenœuds, feuilles et stomates. Agronomie, 6 (7).
Locquin M., Langeron M., 1978. Manuel de Microscopie, Ed. Masson, $352 \mathrm{p}$.

Moss B., 1962. Graft incompatibility in fruit trees. C.A.B. Tech. comm. $\mathrm{n}^{\circ} 28$, East Malling, $36 \mathrm{p}$.

Noiton D., 1981. Contribution à l'étude d'une plante haplö̈de de pommier (Malus pumila, Mill.) - Etude descriptive et comparative avec des clones diploïde, triplö̈de et tétraplö̈de. Maîtrise Biophysiol. appl. aux productions végétales. Université d'Angers, $29 \mathrm{p}$.

Noiton D., 1982. Contribution à l'étude d'une plante haploïde de pommier (Malus pumila, Mill.) - Culture in vitro et essais de diploiddsation. D.E.A. Biol. Physiol. Vég. Univ. Clermont-Ferrand, 28 p.

Skene D. S., Shepherd H. R., Howard B. H., 1983. Characteristic anatomy of union formation in $\mathrm{T}$ - and chip-budded fruit and ornamental trees. J. Hortic. Sci., 58 (3), 295-299.

Thiel K., 1954. Untersuchungen zur Frage der Unverträglichkeit bei Birnenedelsorten auf Quitte A (Cydonia EM A). Gartenbauwis., 1 (19), 127-159. 